\title{
The Changes of Polyphenols, Flavonoids, Anthocyanins and Chlorophyll Content in Plum Peels during Growth Phases: from Fructification to Ripening
}

\author{
Romina A. VLAIC ${ }^{1}$, Vlad MUREŞAN ${ }^{1}$, Andruța E. MUREȘAN ${ }^{1 *}$, \\ Crina C. MUREȘAN ${ }^{1}$, Adriana PĂUCEAN ${ }^{1}$, Viorel MITRE ${ }^{2}$, \\ Simona M. CHIȘ ${ }^{1}$, Sevastița MUSTE ${ }^{1}$ \\ ${ }^{1}$ University of Agricultural Sciences and Veterinary Medicine Cluj-Napoca, Faculty of Food Science and Technology, Food Engineering \\ Department, 64 Calea Floreşti, 400509, Cluj-Napoca, Romania; romina.vlaic@usamvcluj.ro; vlad.muresan@usamvcluj.ro; \\ andruta.muresan@usamvcluj.ro ("correspondingauthor); crina.muresan@usamvcluj.ro; adriana.paucean@usamvcluj.ro; \\ simona.chis@usamvcluj.ro; sevastita.muste@usamvcluj.ro \\ ${ }^{2}$ University of Agricultural Sciences and Veterinary Medicine Cluj-Napoca, Faculty of Horticulture, Horticulture and Landscape Department, \\ 3-5 Mănăștur, 400372, Cluj-Napoca, Romania; viorel.mitre@usamvcluj.ro
}

\begin{abstract}
Samples from 'Stanley', 'Vânăt de Italia' and 'Tuleu Gras' plum cultivars were collected from two different positions of the tree crown (i.e., inside, and periphery of the crown) at six different harvesting times, starting with the phase when plum fruits were the size of a bean until they reached full maturity at 21 days intervals. The main phytochemicals of plum skin during fruit development were analyzed. Total polyphenols from plum skin showed variations throughout the fruit growth (200.6 to $1244.5 \mathrm{mg} \mathrm{GAE} 100 \mathrm{~g}^{-1}$ ), a relatively ascending trend being noticed. For 'Stanley' DPPH-Scavenging Activity, statistically insignificant differences $(p>0.05)$, with values between $47.4 \%$ and $51.5 \%$, were found, similar trends being observed for 'Vânăt de Italia' and 'Tuleu Gras'. The total flavonoid content in the analyzed plum fruits statistically significantly decreased $(p$ $<0.05$ ) from fructification to ripening for 'Stanley' and 'Tuleu Gras'. On the other hand, variations were registered for 'Vânăt de Italia' cultivar which had the highest flavonoid content on the sixth harvesting phase. Anthocyanin content accumulated in 'Vânăt de Italia' plum peel showed increasing values during fruit development, regardless of the harvesting phase, variety or position, while a slightly decreasing trend was found for 'Stanley' and 'Tuleu Gras' varieties. The largest quantity of total chlorophyll $\left(287.4 \mu \mathrm{g} \mathrm{g}^{-1}\right)$ was found in the fructification phase, followed by a continuous decrease until ripening, whatever the variety or crown position.
\end{abstract}

Keywords: anthocyanins, chlorophyll, flavonoids, fruit development, plums phytochemicals, polyphenols

\section{Introduction}

Plums are considered a group of fruits rich in bioactive compounds or phytochemicals such as vitamins (A, C and E), anthocyanin and other phenols and carotenoids (Stacewicz-Sapuntzakis et al., 2001). Plums are known for their high content of phytonutrients and are considered a rich source of natural antioxidants necessary in our daily nutrition. It has been proven that plums have a higher antioxidant capacity than most fruits that are predominant in human nutrition, such as apples, tomatoes, and peaches and similar to that of strawberries and blueberries (Valero and Serrano, 2010). Díaz-Mula et al. (2009) reported significant differences in bioactive compounds of eight plum fruits cultivars, harvested on commercial ripening phase and then cold stored. Four cultivars ('Blackamber', 'Larry Ann', 'Golden Globe' and 'Songold') presented a typical climacteric ripening while other four ('Golden Japan' 'Angeleno', Black Diamond' and 'TC Sun') showed a suppressed-climacteric behaviour. At harvest, variations were reported among studied cultivars, overall, higher antioxidant activity and phytochemical concentration being found in fruits skin than in flesh.

Kayano et al. (2002) claimed that plums are rich sources of phenolic compounds, which, as expected, were correlated 
with their antioxidant capacity, plums being ranked superior to apples, grapes, pears, watermelons, bananas. Cevallos-Casals et al. (2006) showed that plums from 14 cultivars harvested from USDA Fruit and Nut Research (Byron, U.S.) had three to four times higher phenolic concentration in skin as compared to pulp. The mixture, the content and the distribution of phenolic compounds of various cultivars of plums ('Beltsville Elite B70197', 'Cacak Best', 'French Damson', 'Long John', 'Stanley', 'Yugoslavian Elite T101') grown in New York State Agricultural Experiment Station orchard (Geneva, U.S.), were influenced by the fruit maturation, variety characteristics, geographic origins, cultural practices and, storage conditions (Kim et al., 2003). Tomás-Barberán et al. (2001) reported a total amount of Flavan-3-ol between 662 and $1837 \mathrm{mg} \mathrm{g}^{-1}$ (as a catechin equivalent) in the plum skin, while for plum pulp from 138 to $618 \mathrm{mg} \mathrm{kg}^{-1}$, respectively; these compounds being responsible for the plums astringent taste. The same authors showed a progressive growth in the catechin concentration during fruits development, a decrease being reported when the fruits reached maturation. Díaz-Mula et al. (2009) noticed that anthocyanin level was between 20 to 40 times higher in the plum skin, than in the flesh with significant differences among studied varieties grown in Spain; the highest values were registered for fruit skin of 'Black Amber' cultivar $\left(4370 \mathrm{mg} \mathrm{kg}^{-1}\right)$, while the lowest value was found in the skin of 'Black Diamant' plum (1310 $\mathrm{mg} \mathrm{kg}^{-1}$ ).

The chlorophyll is the molecule which absorbs the solar light and uses the energy to synthesize carbohydrates from $\mathrm{CO}_{2}$ and water during the photosynthesis, a basis sustaining vital processes for all plants. Because animals and humans consume plants as part of their nutrition, photosynthesis may also be considered the well of our lives. Within the superior plants, chlorophyll ' $a$ ' $(\mathrm{Ca})$ and ' $b$ ' $(\mathrm{Cb})$ are representative (McGlasson et al., 2007). The degradation of both chlorophyll types appears during the tissues' vegetative senescence, as well as during the fruit ripening. Therefore, chlorophyll content changes are used as a pattern of fruit ripening (Solovchenko et al., 2005). Kader et al. (1999) observed a linear decrease of chlorophyll during the last development period of plum fruit, for both varieties researched, which is agreement with horticultural knowledge of fruits ripening. In another study, Abdi et al. (1997) reported a similar chlorophyll degradation pattern, the studied plum varieties changed the color from green to yellow.

To the best of our knowledge, there is a lack of information regarding the study of the biochemical characteristics during fruit development, for main plum varieties grown in Romania (i.e., 'Stanley'; 'Vânăt de Italia' and 'Tuleu Gras'). Therefore, this paper aims to assess the changes of polyphenols, flavonoids, chlorophyll and anthocyanin content in plum peels during fruit development - from fructification phase to ripe plums. The results obtained will facilitate the selection of optimal harvesting time for plum fruits based on their phytochemical content. In addition, different phytochemical extracts production is possible as a potential superior valorization of fruits physiological falls, which are underused in current horticultural production.

\section{Materials and Methods}

\section{Materials}

The plum varieties selected for the current study were 'Stanley', 'Vânăt de Italia' and 'Tuleu Gras', being widely known plums trees grown in Romania. The samples (between 30 and 60 plums, depending on the size) were harvested from the same trees, in 2013 season, from a farm located in Cluj-Napoca, Cluj Region, Romania. For each of the three varieties studied, the samples were collected from two different positions of the tree crown (i.e., inside, and periphery of the crown), at six different harvesting times, starting with the phase when plum fruits were the size of a bean (27.05.2013) until they reached full maturity (09.09.2013) at 21 days intervals. Consequently, based on the three experimental factors used and their levels (i.e., Variety [3], Position [2], and Harvesting phase [6]), the resulted research design $(3 \times 2 \times 6)$ included 36 different samples. After each harvesting, the samples were individually vacuumed and stored at $-18{ }^{\circ} \mathrm{C}$, until further analysis.

\section{Samples extraction}

In order to assess the antioxidant capacity, the total phenolic, flavonoids, anthocyanin content, plum skin extractions were obtained as described by Abdel-Aal et al. (2002) with some minor modifications. For each extraction, the skin from 3 to 5 plums was used, chopped and mixed using a mortar. From each sample, $1 \mathrm{~g}$ was collected and homogenized with methanol containing $0.01 \% \mathrm{HCl}$ in plastic tubes. The samples were centrifuged 5 minutes at $5000 \mathrm{rpm}$, the plant material being subjected to minimum three successive extractions, while all supernatants were collected. The obtained extracts were filtered and dried at $35{ }^{\circ} \mathrm{C}$ under reduced pressure (Heidolph Rotary Evaporator). Finally, the dried extracts were dissolved in a known volume (from 6 to $8 \mathrm{ml}$ of methanol) and stored at $-20^{\circ} \mathrm{C}$, until further analysis.

\section{Determination of total polyphenol content by Folin- Ciocâlteu method}

The total polyphenols content was assessed using the Folin-Ciocâlteu method (Singleton et al., 1999), slightly modified. A quantity of $25 \mu$ l sample was mixed with $1.8 \mathrm{ml}$ of distilled water and $120 \mu \mathrm{l}$ Folin-Ciocâlteu reagent in a glass vial. $\mathrm{A} \mathrm{Na} \mathrm{Na}_{2} \mathrm{CO}$ 7.5\% solution in distilled water $(340$ $\mu \mathrm{l})$, was added 5 minutes later, to assure basic conditions (pH 10) for the Redox reaction between the phenolic compounds and the Folin-Ciocâlteu reagent. The samples were incubated for 90 minutes at room temperature. Methanol was used as a control sample. The absorbance at $750 \mathrm{~nm}$ was measured using a Shimadzu UV-VIS 1700 spectrophotometer. The calibration curve was plotted based on the $0.25,0.50,0.75,1 \mathrm{mg} \mathrm{ml}^{-1}$ concentration of gallic acid. The total polyphenol content of plum fruit skin was expressed for fresh weight (FW) in Gallic acid equivalents (GAE) - mg GAE 100g. .

\section{Estimation of total flavonoid content}

The total flavonoid content in the plum fruit skin extracts was assessed using the colorimeter method, as 
150

described by Kim et al. (2003). The alcoholic extracts were diluted with distilled water up to $5 \mathrm{ml}$, adding $300 \mu \mathrm{l}$ of $5 \%$ $\mathrm{NaNO}_{2}$ solution. After 5 minutes, the mixture was treated with $300 \mu \mathrm{l} \mathrm{AlCl}{ }_{3} 10 \%$ solution and 6 minutes later, with 2 $\mathrm{ml} \mathrm{NaOH} 1 \mathrm{~N}$ solution. The absorbance was read at $500 \mathrm{~nm}$ using a UV-VIS 1700 Shimadzu spectrophotometer, the total flavonoid content, being expressed in mg quercetin equivalent for $100 \mathrm{~g}$ of fresh sample.

\section{Quantification of total anthocyanins}

The total anthocyanins were extracted from plum fruit skin using the method described by Diaconeasa et al. (2015) and were determined using the $\mathrm{pH}$ differential method. The monomeric anthocyanin pigments change color reversible with the changing of the $\mathrm{pH}$. At $\mathrm{pH} 1.0$ a colored, oxonium compound is formed, while at $\mathrm{pH} 4.5$ the transparent, hemiketal form is predominant. The pigment difference of absorption at $520 \mathrm{~nm}$ is proportional with the pigment concentration. The results were expressed using cyanidin-3-glucoside equivalent.

Two dilutions were prepared from the same sample, the first in potassium chloride buffer solution $(0.025 \mathrm{M}, \mathrm{pH}$ $1.0)$, and the second in sodium acetate buffer solution (0.4 $\mathrm{M}, \mathrm{pH} 4.5$ ), the $\mathrm{pH}$ been adjusted using $\mathrm{HCl}$. The samples were equilibrated at room temperature for 15 minutes. The absorbance was read at 520 and $700 \mathrm{~nm}$, using the spectrophotometer Shimadzu UV-VIS 1700.

The total anthocyanins ( $\mathrm{mg}$ cyanidin-3-glucoside equivalent $\left.\mathrm{L}^{-1}\right)$ were calculated as follows:

Antocyanins content $\left(\mathrm{mg} \mathrm{L}^{-1}\right)=(\mathrm{A} \times \mathrm{MW} \times \mathrm{DF} \times$ $1000) / \varepsilon \times$ L, where: $\mathrm{A}=(\mathrm{A} 520 \mathrm{~nm}-\mathrm{A} 700 \mathrm{~nm} \mathrm{pH} 1.0)-$ $($ A520 nm - A700 nm pH 4.5); MW = molecular weight for cyanidin-3-glucoside (cyd-3-glu), $449.2 \mathrm{~g} \mathrm{~mol}^{-1} ; \mathrm{DF}=$ dilution factor; $10^{3}=$ the transformation factor from $g$ to $\mathrm{mg} ; \varepsilon=26900$ molar extinction coefficient, in $\mathrm{L} \times \mathrm{mol}^{-1} \times$ $\mathrm{cm}^{-1}$ for cyn-3glu; $1=$ cell path length $(1 \mathrm{~cm})$ (Giusti and Wrolstad, 2001).

\section{DPPH-scavenging activity}

The antioxidant capacity was determined by assessing the Free Radical Scavenging effect over 1,1-diphenyl-2picrylhydrazyl radical (DPPH) (Odriozola-Serrano et al., 2008). The antioxidant activity was calculated as follows:

DPPH scavenging effect $(\%)=\left[\left(A_{0}-A_{s}\right) \times 100\right] / A_{0}$

where, $A_{0}$ is absorbance of the blank, and $A_{s}$ is absorbance of the samples.

\section{Assessment of chlorophyll content}

The extraction of chlorophyll from the plum skin was performed according to the method described by Lancaster et al. (1994) with some modifications. Absorbance was measured at 645 and $663 \mathrm{~nm}$. Chlorophyll content was calculated using the equations:

$C a\left(\mathrm{mg} \mathrm{g}^{-1}\right)=[(12.7 \times \mathrm{A} 663)-(2.6 \times \mathrm{A} 645)] \times \mathrm{ml}$ acetone / $\mathrm{mg}$ sample

$C b\left(\mathrm{mg} \mathrm{g}^{-1}\right)=[(22.9 \times \mathrm{A} 645)-(4.68 \times \mathrm{A} 663)] \times \mathrm{ml}$ acetone / $\mathrm{mg}$ sample

$\mathrm{CT}=\mathrm{Ca}+\mathrm{Cb}$

where: $C a$ - chlorophyll $a$; $C b$ - chlorophyll b; A663 absorbance at $663 \mathrm{~nm}$; A645-absorbance at $645 \mathrm{~nm}$; CTtotal chlorophyll (Arnon, 1949).

\section{Statistical analysis}

The analysis of variance was performed using Minitab 16.1.0, Tukey comparison tests being also included at a significance level $\alpha=0,05$. Classical and relative eta-squared, used to compare the effects of different factors in the same design, were computed.

\section{Results and Discussion}

\section{Changes of total polyphenol content (TPC)}

Total polyphenols from plum skin showed variations throughout the fruit growth, as showed in Fig. 1 for 'Stanley' variety TPC recorded values between $200.6 \mathrm{mg}$ GAE $100 \mathrm{~g}^{-1}$ and $568.3 \mathrm{mg} \mathrm{GAE} 100 \mathrm{~g}^{-1}$; for 'Vânăt de Italia' variety TPC recorded values were between $201.6 \mathrm{mg}$ GAE $100 \mathrm{~g}^{-1}$ and $1244.5 \mathrm{mg} \mathrm{GAE} 100 \mathrm{~g}^{-1}$; in the case of 'Tuleu

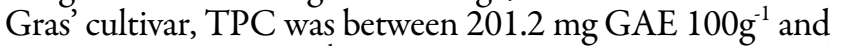
$378.4 \mathrm{mg} \mathrm{GAE} 100 \mathrm{~g}^{-1}$. It is interesting to notice - and somehow difficult to explain - the recorded TPC variations obtained for the plums skin of the three varieties during fruits development, which most probably could be related to climate conditions in 2013. Similar variations were also noticed by Chun et al. (2004) when analysing 13 different plum cultivars, TPC ranged from $138.1 \pm 2.9 \mathrm{mg} \mathrm{GAE}$ $100 \mathrm{~g}^{-1}$ to $833.6 \pm 4.8 \mathrm{mg}$ GAE $100 \mathrm{~g}^{-1}$. Marinova et al. (2005) found a TPC of $303.6 \mathrm{mg} \mathrm{GAE}^{100 \mathrm{~g}^{-1}}$ in ripe plums harvested from Bulgaria.

It is generally well known that during fruit ripening, the phenolic concentration lowers, while the flavonoids concentration grows (Manach et al., 2004). Amiot et al. (1995) investigated the influence of the maturity phase on the phenolic content of three pears varieties ('Williams', 'Harow Sweet' and 'Guyot') at three different times of the year, variations among cultivars being observed: TPC of 'Williams' variety tended to increase and subsequently decrease, whereas 'Harow Sweet' decreased continuously to ripening time. Conversely, 'Guyot' plums TPC increased during fruit development. The TPC variations observed in the current study are supported by Miletić et al. (2012), which attributed the lack of a clear trend concerning TPC to the variations in composition of compounds that fall within phenols group during ripening. In other words, the degradation of some phenols was faster or slower than the biosynthesis of other phenols. Moreover, a reversed correlation between the phenolic compounds concentration and air temperature was reported (Xu et al., 2011), similar results being observed in the current study.

\section{Changes of total flavonoid content}

The highest flavonoid content was found in the skin of the 'Vânăt de Italia' plum variety, in the $6^{\text {th }}$ harvesting phase, for the fruits collected from the periphery of the crown. The changes of total flavonoid content of plum skin during fruit development is presented in Fig. 2

The flavonoid content varied between $55.3 \mathrm{mg}$ QE $100 \mathrm{~g}^{-1}$ and $190 \mathrm{mg} \mathrm{QE} 100 \mathrm{~g}^{-1}$ for the 'Stanley' variety,

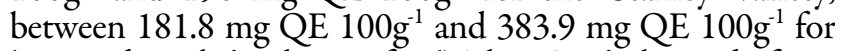
'Vânăt de Italia', whereas for 'Tuleu Gras' changed from $63.9 \mathrm{mg}$ QE $100 \mathrm{~g}^{-1}$ to $133.5 \mathrm{mg}$ QE $100 \mathrm{~g}^{-1}$. Similar results were obtained by Kim et al. (2003) for 11 plum varieties, flavonoid content varying between $64.8 \mathrm{mg}^{\mathrm{QE}} 100 \mathrm{~g}^{-1}$ and 
$257.5 \mathrm{mg}$ QE $100 \mathrm{~g}^{-1} \mathrm{FW}$. In another study, Miletić et al. (2013) reported a total flavonoid content of $207.9 \mathrm{mg}$ QE $100 \mathrm{~g}^{-1}$ and $100.4 \mathrm{mg} \mathrm{QE} 100 \mathrm{~g}^{-1}$, for dried plums of the 'Valjevka' and 'Mildora' varieties, while emphasizing that the drying process did not influence the amount of flavonoids; Veličković et al. (2014) found a flavonoid content of $131 \mathrm{mg}$ QE $100 \mathrm{~g}^{-1}$ for Prunus spinosa L. fruits methanolic extract. Several authors found similar oscillations regarding the amount of flavonoids during the maturation process of the plum fruit, for example Stöhr et al. (1975) showed that the flavonoids concentration decreases as the fruits were ripening. Tomás-Barberán et al. (2001) reported for 'Black Beaut' and 'Angeleno' that the amount of flavonoids increased together with fruit maturation, whereas for the 'Wickson' variety, the amount of flavonoids decreased once the fruits reached maturation. Same authors indicated also great taste differences among studied fruits, while flavonoids were responsible for the plum stringency.

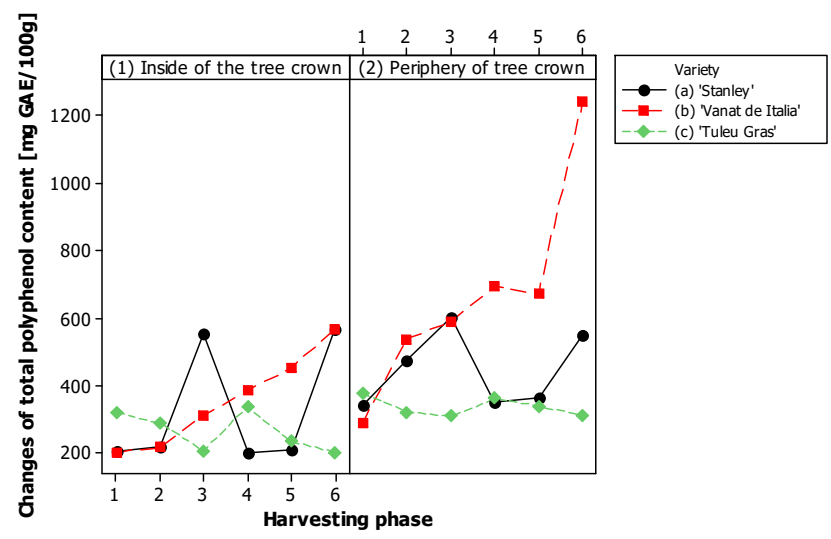

Fig. 1. Changes of total polyphenol content in the skin of plum fruits collected from different crown positions at six different harvesting times

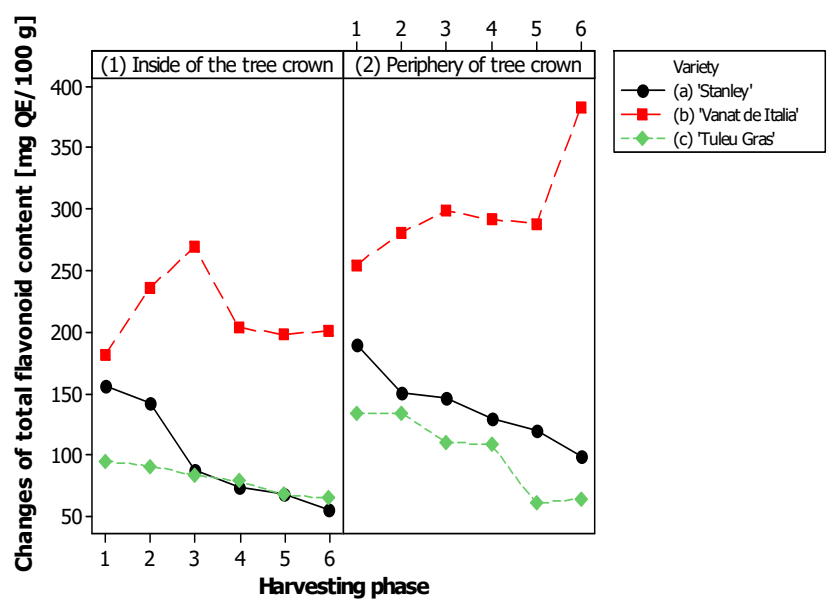

Fig. 2. Changes of total flavonoid content in the skin of plum fruits collected from different crown positions at six different harvesting times

\section{Changes of anthocyanin content}

The anthocyanin content in the plum skin of the three varieties studied ('Stanley', 'Vânăt de Italia' and 'Tuleu Gras') and harvested during fruit development from different positions in the tree crown (interior and periphery of the crown), was determined when the first purple color traces were noticed on the fruits surface (harvesting phases 4, 5 and 6), their trend being shown in Fig. 3. The anthocyanins accumulated in the plum skin registered increasing values irrespective of the harvest, variety or position. Thus, for the fruits harvested from inside of the tree crown, the 'Stanley' variety recorded values between 1.11 and $184.09 \mathrm{mg} \mathrm{CE} 100 \mathrm{~g}^{-1}$, 'Vânăt de Italia' between

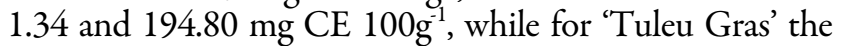
anthocyanins were increasing slowly from 6.24 to $45.96 \mathrm{mg}$ $\mathrm{CE} 100 \mathrm{~g}^{-1}$. For the fruits harvested from the crown periphery, the anthocyanin content was between 25.56 $261.93 \mathrm{mg} \mathrm{CE} 100 \mathrm{~g}^{-1}$ for 'Stanley', 6.87 - $306.98 \mathrm{mg} \mathrm{CE} 100$

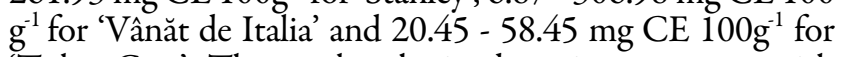
'Tuleu Gras'. The results obtained are in agreement with Vizzotto et al. (2007) study, where the anthocyanin content of 45 ripe plums and peaches cultivars with differently colored skin and pulp were determined. A similar trend of anthocyanin accumulation for 'Valor', 'Čačanska rodna', 'Čačanska najbolja', and 'Jojo' varieties, was found by Usenik et al. (2009) for fruits harvested in 6 different phases during development, all varieties showing the highest amount of anthocyanins either in the penultimate or last sampling time. Lancaster et al. (1997) observed that the distribution of anthocyanin in the skin and their concentration is mainly influenced by factors such as light, temperature, ethylene and cultural practices. Ripening of fruits is associated with the biochemical changing of the color, texture, taste and other quality characteristics; consequently it has an important effect over the anthocyanin changes of plum fruits. In the current study, it was found that the anthocyanin content showed different trends as influenced by plum variety (Fig. 3). Diaz-Mula $e t$ al. (2009) studied the amount of anthocyanin in 4 purple red varieties of plums, for both fruit's skin as well as their pulp, reporting differences of 20 up to 40 times higher anthocyanin content found in the skin, as compared with the pulp; similarly, Cevallos-Casals et al. (2006) reported differences from 7 up to 9 times higher, while TomásBarberán et al. (2001) identified differences up to 13 times higher anthocyanin content in plum skin as compared to the pulp.

\section{DPPH-scavenging activity}

The antioxidant activity of fruits is directly influenced by the phenolic compounds, and in lower amount to Vitamin C and carotenoids (Guorong et al., 2009). The DPPH-Scavenging Activity of the plum skin for 'Stanley' variety recorded statistically insignificant differences $(p>$ 0.05 ) with values between $49.1 \%$ and $51.5 \%$ when fruits were collected from inside the crown and between $47.4 \%$ and $50.2 \%$ for the periphery of the crown, samples being analyzed at different harvesting times. Similar trends were noticed for the other two plum cultivars studied 'Vânăt de Italia' and 'Tuleu Gras', as shown in Fig. 4. DPPHScavenging Activity variations were also reported by Miletić et al. (2012) for 'Stanley' plums during five harvesting 
152

phases ( 7 days between sampling) in three consecutive years, no trend being noticed during fruit development. Same conclusions were drawn by Kristl et al. (2011) when analysing four plum varieties 'Valor', 'Stanley', 'Hanita' and 'Tophit', in the last weeks of ripening. Differences in antioxidant capacity depending on the variety during maturation of several plum varieties grown under the same conditions were reported by Díaz-Mula et al. (2009), confirming that the variety has a significant role for antioxidant capacity.

\section{Chlorophyll content}

Comparing the chlorophyll content of fruits skin for the three plum varieties studied, a decreasing trend was found, whatever the variety or the crown harvesting positions, as can be noticed in Fig. 5. Statistically significant differences $(p<0.05)$ were observed as a function of harvesting phase, the largest amount of $C a, C b$ and CT was found in the first harvesting phase, while the lowest in the last. Kader $e t$ al. (1999) have observed a linear decrease in chlorophyll absorption in the last development of plum fruit on the tree for both varieties studied, which corresponds physiologically and horticulturally with the growth and maturation of the fruit. Abdi et al. (1997) stated that green-to-yellow color change for prunes in its research is associated with

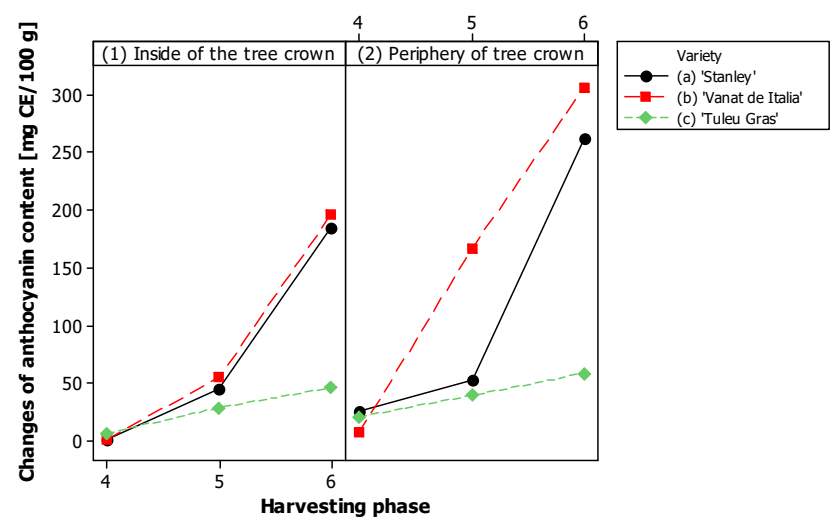

Fig. 3. Changes of antocyanin content in the skin of plum fruits collected from different crown positions at six different harvesting times

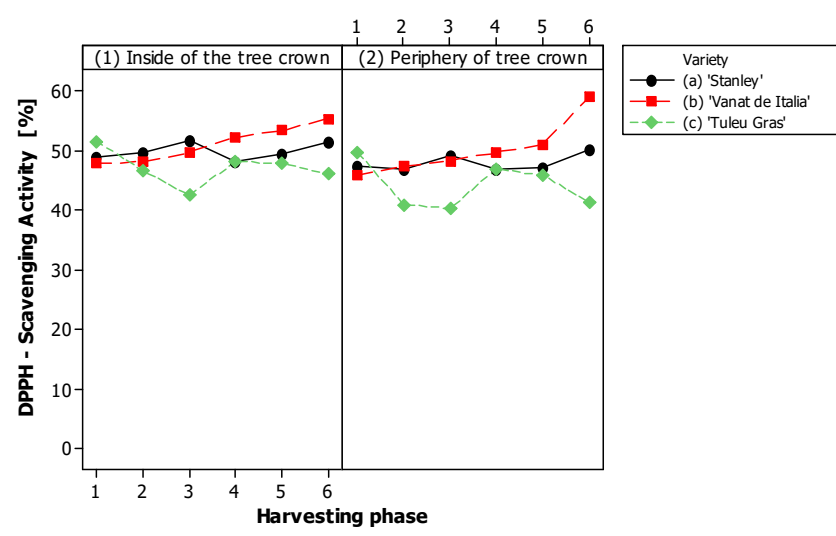

Fig. 4. Changes of DPPH-scavenging activity in the skin of plum fruits collected from different crown positions at six different harvesting times chlorophyll degradation during fruit baking. A decrease of the chlorophyll content by $41 \%$ during 12 days of ripening, was also reported for the peel of 'Qingnai' plums (Prunus salicina Lindl.), once the fruits color changed to purple red (Luo et al., 2009). The chlorophyll absorption might be a certain method to determine the real maturation stage of the fruits. High correlations between the chlorophyll absorption and the level of maturation were reported for several fruits, including plums (Ziosi et al., 2008; Infante et al., 2011). Moreover, the absorption of chlorophyll could be a reliable method to determine the actual ripeness state of the plum fruit (Infante et al., 2011).

Regarding the position of the fruit in the crown of the tree for each variety, statistically significant differences $(p<$ $0.05)$ for $C a$ and $C b$ were noticed. A higher amount of chlorophyll is found in the fruit harvested from the inside of the crown, compared to the fruits harvested at the crown's periphery. This could be attributed to the uneven distribution of light in the crown of the tree, as observed by Jacques et al. (2010).

The effect of variety, crown position and harvesting phase on the antioxidant activity, total polyphenol, flavonoids, anthocyanin and chlorophyll contents

The Analysis of variance revealed that the main effects, Variety, Crown Position and Harvesting phase indicated high significant differences $\left({ }^{* * *} ; p<0.001\right)$ for all studied phytochemicals characteristics, as shown in Fig. 6. First and second order interactions for total polyphenol, flavonoids and anthocyanin content showed also high significant differences $\left.{ }^{* * *} ; p<0.001\right)$. Typically, the existence of a significant interaction exerts a null effect for subsequent interpretation of its inferior interactions and its principal effects. Consequently, essential is the discussion of the statistically significant second order interaction, the Variety * Position * Harvesting Phase for polyphenols, flavonoids and anthocyanins, as already performed in the previous section.

In order to emphasize the contribution of each factor or interaction, relative eta squared was computed as the proportion of total variation attributable to each factor or interaction. For each biochemical characteristic, a pie chart was used for displaying the proportion of total variance that corresponds to experimental factors and interactions (Fig. 6, sections A to E); the entire pie represents the total sum of squares, while each slice, expressed in percentages, is the effect size. For the antioxidant activity the first order interaction Variety ${ }^{*}$ Harvesting phase showed high significant differences $\left.{ }^{* * *} ; p<0.001\right)$ while the remaining interactions were statistically insignificant $(p>0.05)$ with a very low importance on the total variability. In the case of chlorophyll, the first order interactions Variety * Position and Position * Harvesting Phase, as well as the second order interaction of Variety * Position * Harvesting Phase showed very significant differences $\left.{ }^{* * *} ; p<0.001\right)$, the interaction between Variety ${ }^{*}$ Position being statistically insignificant $(p$ $>0.05$ ). The main effects Variety, Crown Position and Harvesting phase explained $19 \%, 18.6 \%$, and $17.3 \%$ of the total variability of total polyphenol content in the skin of plum fruits (Fig. 6). One can also notice the weight of the Variety ${ }^{*}$ Harvest Phase interaction which accounted for 
$29.8 \%$, while the other interactions gather together $8.2 \%$.The main effect Variety explained $75.1 \%$ of the total variability of flavonoid content in the plum skin, indicating the particular importance of the Variety for this characteristic, while the principal interaction was Variety* Harvesting phase with $7.1 \%$. In the case of anthocyanins the main effect Harvesting Phase explained 55.2\%, Variety $16.1 \%$ and Position only 5.1\%, thus strengthening the significance of harvesting phase in the variability of the anthocyanins in the plum skin during fruits development. Among the most important interactions was the Variety * Harvesting phase, which registered $18.3 \%$ of the anthocyanin variability, while the remaining interactions altogether had less than 5\%. For the antioxidant capacity the main effects: Variety, Harvesting Phase and Crown Position explain $29.5 \%, 12.2 \%$ and $6.5 \%$ respectively, indicating the particular meaning of the Variety. At the same time, this statistical analysis explained the very high influence $(38.7 \%)$ of the Variety ${ }^{*}$ Harvest Phase interaction of the antioxidant capacity variability in the plum skin, while the remaining interactions are less than $5.7 \%$. The experimental factor Harvesting Phase explained $81.9 \%$ of the total chlorophyll variability, indicating, as expected, the high significance of the time of harvest on the chlorophyll content.

Concerning the chlorophyll content, the statistical tests performed, showed the influence of the Variety (explained $9.7 \%$ of the variability) and the low importance of the Crown position effect (1.7\%). Among interactions the highest weight was recorded for the Variety * Harvesting phase (6\% of the total variability), while the other interactions gather together less than $0.6 \%$.
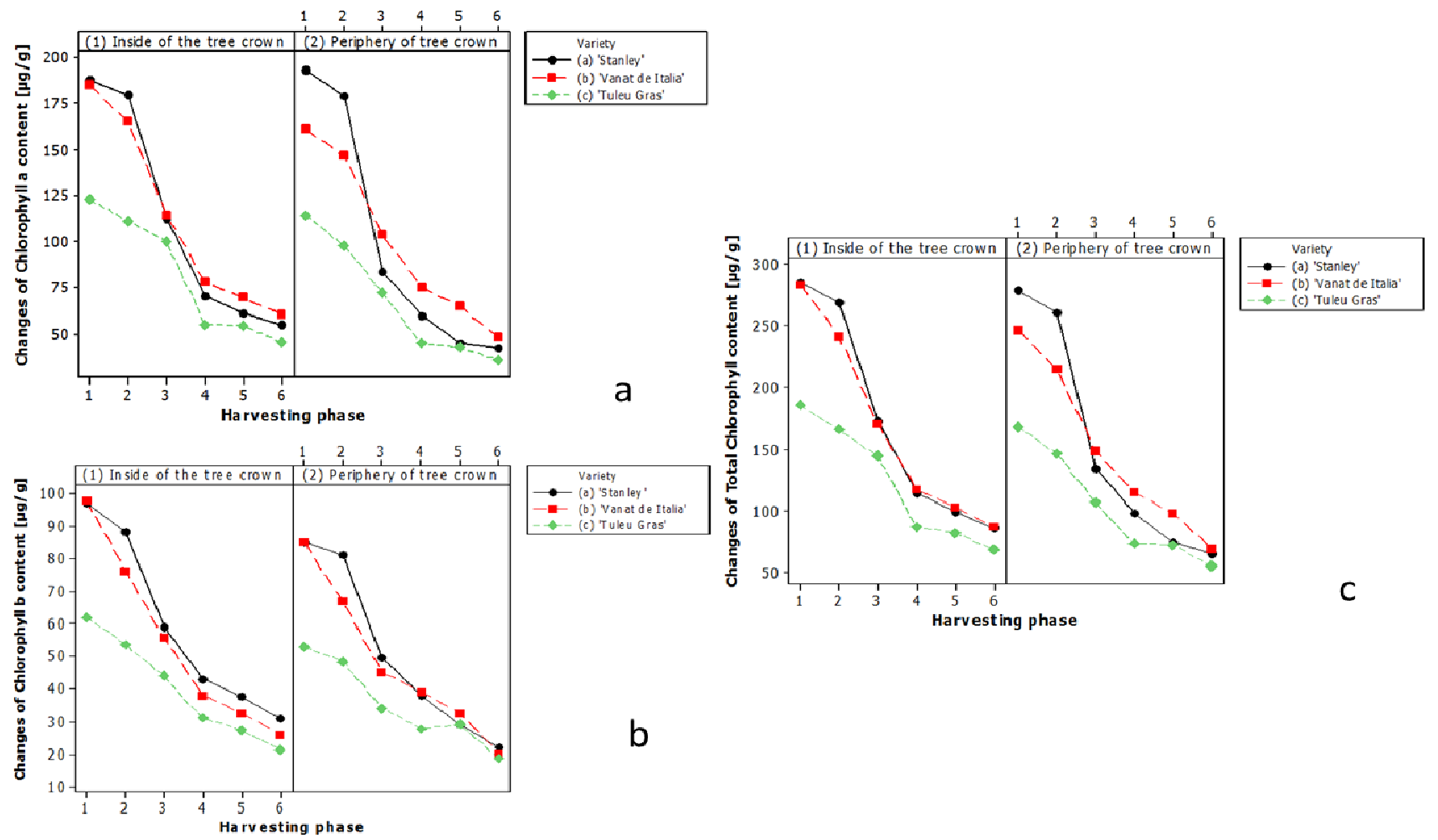

Fig. 5. Changes of chlorophyll a (A), chlorophyll b (B) and total chlorophyll (C) contents in the skin of plum fruits collected from different crown positions at six different harvesting times

\section{Conclusions}

The total polyphenol content in the plums peel showed variations during the fruits growth for all three studied cultivars and crown positions used for harvesting the samples. As expected, a similar trend was highlighted in the case of antioxidant capacity. The total flavonoid content of the analyzed plums peel registered significantly decreasing values $(p<0.05)$ during fruits maturation; the exception was the plum peel of 'Vânăt de Italia' variety harvested from the periphery of the crown, which registered an unexpected high value (383.9 $\mathrm{mg} \mathrm{QE} 100 \mathrm{~g}^{-1}$ ) on the last harvesting phase. Anthocyanin content accumulated in 'Vânăt de Italia' plum peel showed increasing values during fruit development, regardless of the harvesting phase, variety or position, while a slightly decreasing trend was found for 'Stanley' and 'Tuleu Gras' varieties. The highest content of $C a, C b$ and total chlorophyll was found in the first harvesting phase, while decreasing continuously to the last harvesting phase, for all studied varieties, regardless of crown positions. The present study recommends valorizing the plum fruit skin resulted as a by-product, as well as the fruits resulted from physiological falls for antioxidant extractions or natural dyes. The flavonoids and chlorophyll are more abundant during the immature stage of plum fruits, whereas the quantity of anthocyanin reaches the highest values during plum fruit ripening. 

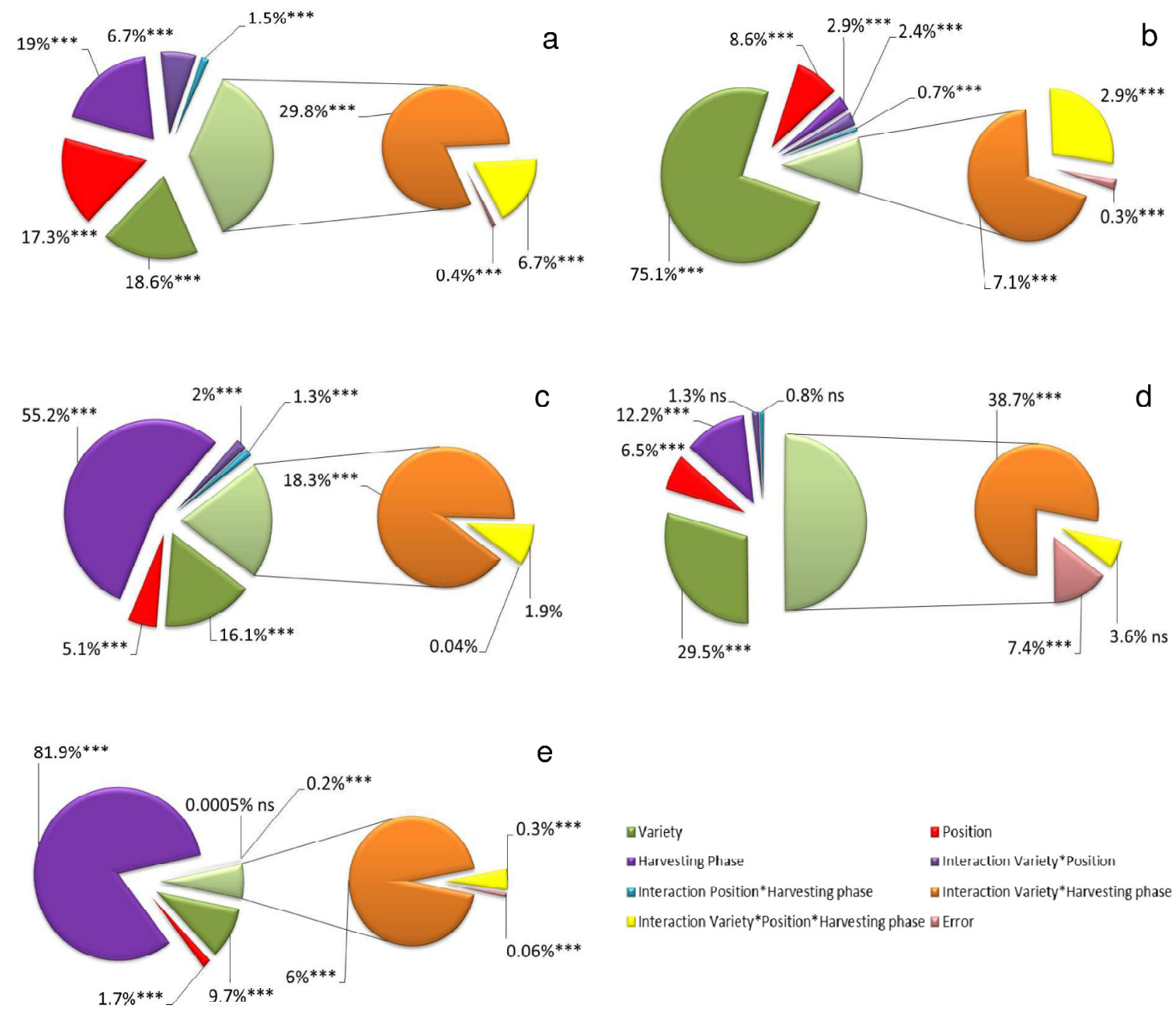

Fig. 6. The relative eta squared effect sizes on the total polyphenol content (A), total flavonoids content (B), anthocyanin content $(C)$, antioxidant activity (D), chlorophyll content (E) of skin plums for the studied factors and their interactions $\left(p\right.$ - value: * ${ }^{*}$ significant $(p<0.05) ;{ }^{* *}$ very significant $(p<0.01) ;{ }^{* *}$ high significant $(p<0.001)$; ns - insignificant $\left.(p>0.05)\right)$

\section{Acknowledgements}

This paper was published under the frame of European Social Fund, Human Resources Development Operational Program 2007-2013, project no. POSDRU/159/1.5/S/ 132765. This work was also supported by a grant of the Romanian National Authority for Scientific Research and Innovation, CNCS/CCCDI-UEFISCDI, project number PN-III-P2-2.1-BG-2016-0122 within PNCDI III.

\section{References}

Abdel-Aal ES, Young JC, Wood PJ, Rabalski I, Hud P, Falk D, FregeauReid J (2002). Einkorn: A365 potential candidate for developing high lutein wheat. Cereal Chemistry79(3):455-457.

Abdi N, Holford P, McGlasson WB (1997). Effects of harvest maturity on the storage life of Japanese-variety plums. Australian Journal of Experimental Agriculture 37:391-397.

Amiot MJ, Tacchini M, Aubert SY, Oleszekz W (1995). Influence of cultivar, maturity stage, and storage conditions on phenolic composition and enzymatic browning of pear fruits. Journal of Agricultural and Food Chemistry 43:1132-1137.
Arnon DI (1949). Copper enzymes in isolated chloroplasts. Polyphenoloxidase in Beta vulgaris. Plant Physiology24:1-15.

Cevallos-Casals BA, Byrne D, Okie WR, Cisneros-Zevallos L (2006). Selecting new peach and plum genovarietys rich in phenolics compounds and enhanced functional properties. Food Chemistry 96:273-280.

Chun OK, Dae-Ok K (2004). Consideration on equivalent chemicals in total phenolic assay of chlorogenic acid-rich plums. Food Research International 37(4):337-342.

Diaconeasa Z, Leopold L, Rugină D, Ayvaz H, Socaciu C (2015). Antiproliferative and antioxidant properties of anthocyanin rich extracts from blueberry and blackcurrant juice. International Journal of MolecularSciences 16(2):2352-2365.

Díaz-Mula HM, Zapata PJ, Guillén F, Martínez-Romero D, Castillo S, Serrano M (2009). Changes in hydrophilic and lipophilic antioxidant activity and related bioactive compounds during postharvest storage of yellow and purple plum cultivars. Postharvest Biology and Technology 51:354363.

Giusti MM, Wrolstad RE (2001). Characterization and measurement of anthocyanins by UV-visible spectroscopy. In: Current Protocols in 
Food Analytical Chemistry.John Wiley \& Sons, New York, USA

Guorong DU, Mingun LI, Fengwang MA, Dong L (2009). Antioxidantcapacity and the relationship with polyphenol and Vitamin Cin Actinidia fruits. Food Chemistry 113:557-562.

Infante R, Rubio P, Contador L, Noferini M, Costa G (2011). Determination of harvest maturityof D'Agen plums through the chlorophyll absorbance index. Ciencia e Investigación Agraria 38(2):199-203.

Jacques R, Fouche SC, Roberts S, Midgley J, Steyn W (2010). Peel color and blemishes in 'Granny Smith' apples in relation to canopy light environment. American Society for Horticultural Science 45(6):899905.

Kader AA (1999). Fruit maturity, ripening, and quality relationships. Acta Horticulturae 485:203-208.

Kayano S, Kikuzaki H, Fukutsaka N, Mitani T, Nakatani N (2002). Antioxidant activity of prune (Prunus domestica L.) constituents and a new synergist. Journal of Agricultural and Food Chemistry 50(13):3708-3712.

Kim DO, Jeong SW, Lee CY (2003). Antioxidant capacity of phenolic phytochemicals from various cultivars of plums. Food Chemistry 81:321-326.

Kristl J, Metka S, Tojnko S, Unuk T (2011). Extractable antioxidants and non-extractable phenolics in the total antioxidant activity of selected plum cultivars (Prunus domestica L.): Evolution during on-tree ripening. Food Chemistry 125:29-34.

Lancaster JE, Jan E, Garant E, Lister CE (1994). Skin color in apple influence of copigmentation and plastid pigments on shade and darkness of red color in five genovarietys. Journal of the American Society for Horticultural Science 119(1):63-69.

Lancaster JE, Lister CE, Reay PF, Trigs CM (1997). Influence of pigment composition on skin colour in a wide range of fruit and vegetables. Journal of the American Society for Horticultural Science 122:594-598.

Luo Z, Xie J, Xu T, Zhang L (2009). Delay ripening of 'Qingnai' plum (Prunus salicina Lindl.) with 1-methylcyclopropene. Plant Science 177:705-709.

Marinova D, Ribarova F, Atanassova M (2005). Total phenolics and total flavonoids in Bulgarian fruits and vegetables. Journal of the University of Chemical Technology and Metallurgy 40(3):255-60.

Manach C, Scalbert A, Morand C, Remesy C, Jimenez L (2004). Polyphenols: food sources and bioavailability. The American Journal of Clinical Nutrition 79:727-747.

McGlasson B, Graham D, Joyce D (2007). Postharvest: An introduction to the physiology and handling of fruit, vegetable and ornamentals. UNSW Press.

Miletić N, Popović B, Miletić O, Kandić M (2012). Phenolic content and antioxidant capacity of fruits of plum cv. Stanley (Prunus domestica L.) as influenced by maturity stage and on-tree ripening. Australian Journal of CropScience 6(4):681-687.
Odriozola-Serrano I, Soliva-Fortuny R, Marti'Nbelloso O (2008). Effect of minimal processing on bioactive compounds and color attributes of fresh-cut tomatoes. LWT-Food Science and Technology 41:217-226.

Singleton VL, Orthofer R, Lamuela-Raventós RM, Lester P (1999). Analysis of total phenols and other oxidation substrates and antioxidants by means of Folin-Ciocâlteu reagent. Methods in Enzymology 299:152178.

Solovchenko AE, Chivkunova OB, Merzlyak MN, Gudkovsky VA (2005). Relationships between chlorophyll and carotenoid pigments during onand off-tree ripening of apple fruit as revealed non-destructively with reflectance spectroscopy. Postharvest Biology and Technology 38:9-17.

Stacewicz-Sapuntzakis M, Bowen PE, Hussain EA, Damayanti-Wood BI, Farnsworth NR (2001). Chemical composition and potential health effects of prunes: A functional food?. Reviews in Food Science and Nutrition 41(4):251-286.

Stöhr H, Mosel HD, Herrmann K (1975). The phenolics of fruits. VII. The phenolics of cherries and plums and the changes in catechins and hydroxycinnamic acid derivatives during the development of fruits. $\mathrm{Z}$ Lebensm Unters-Forsch 159:85-91.

Tomás-Barberán FA, Gil MI, Cremin P, Waterhouse AL, Hess-Pierce B, Kader AA (2001).Hplc-Dad-Esims analysis of phenolics compounds in nectarines, peaches, and plums. Journal of Agricultural and Food Chemistry 49:4748-4760.

Usenik V, Štampar F, Veberič R (2009). Anthocyanins and fruit colour in plums (Prunus domestica L.) during ripening. Food Chemistry 114:529534.

Valero D, Serrano M (2010). Posthravest biology and technology for preserving fruit quality. CRC Press - Taylor and Francis Group USA pp $27-42$.

VeličkovićJM, Kostić DA, Stojanović GS, Mitić SS, Mitić MN, Ranđelović SS, Đorđević AS (2014). Phenolic composition, antioxidant and antimicrobial activity of the extracts from Prunus spinosa L. fruit. Hemijska Industrija 68(3):297-303.

Vizzotto M,Cisneros-Zevallos L, ByrneDH (2007). Large variance found in the phytochemical and antioxidant activity of peach and plum germplasm. Journal American Society Horticultural Science 132:334 340.

Xu C, Zhang Y, Zhu L, Huang Y, LuJ (2011). Influence of growing season on phenolic compounds and antioxidant properties of grape berries from vines grown in subtropical climate. Journal of Agricultural and Food Chemistry 59:1078-1086.

Ziosi V, Noferini M, Fiori G, Tadiello A, Trainotti L, Casadoro G, Costa G (2008). A new index based on vis spectroscopy to characterize the progression of ripening in peach fruit. Postharvest Biology Technology 49:319-329. 